\section{American College of Rheumatology/ European League Against Rheumatism classification criteria for IgG4-related disease by Wallace et al}

We read with interest the original article by Wallace et al proposing the new classification for IgG4-related disease (IgG4RD). ${ }^{1}$ So far, the comprehensive diagnostic criteria for IgG4-RD (the comprehensive criteria) have been widely used, ${ }^{2}$ but recently, the 2019 American College of Rheumatology (ACR) and the European League Against Rheumatism (EULAR) classification criteria for IgG4-RD have been developed and validated (the 2019 ACR/EULAR criteria). To determine the agreement rate between the comprehensive and the 2019 ACR/EULAR criteria, we applied the 2019 ACR/EULAR criteria to 40 patients with definite IgG4-RD based on the comprehensive criteria and retrospectively reviewed their medical records. Based on the inclusion criteria of the 2019 ACR/EULAR criteria, total points of $\geq 20$ indicated the classification of IgG4-RD.

The mean age of the patients was 60.2 years, and 29 patients $(72.5 \%)$ were men. With respect to the immunostaining items, no points were assigned to five patients for lymph node biopsy, although they exhibited both $\operatorname{IgG} 4+/ \operatorname{IgG}+$ cells ratio of $>40 \%$ and IgG4 + cells/high power field (HPF) of $>10$ on immunostaining. Finally, 1 of 40 patients $(2.5 \%)$ with definite IgG4-RD was not reclassified as having IgG4-RD according to the 2019 ACR/EULAR criteria. The 2019 ACR/EULAR criteria do not approve the results of immunostaining if the disease involves the lymph nodes. We described five patients who received no points with respect to the immunostaining items in the 2019 ACR/EULAR criteria in table 1.

Patient 1 exhibited neither information on typical histopathological features of IgG4-RD nor definite evidence of IgG-RD involvement in the chest, pancreas and biliary tree, kidney or retroperitoneum. Thus, patient 1 obtained only 4 points and could not be reclassified as having IgG4-RD despite the increased concentration of serum IgG4 (4 points). Patient 2 exhibited dense lymphocytic infiltrate and storiform fibrosis in the biopsy samples (13 points) and the highest serum IgG4 concentration range (11 points). Patients 3 and 4 exhibited no information on typical histopathological features of IgG4-RD. However, they had the highest serum IgG4 concentration range and definite evidence of IgG-RD involvement in the chest and kidney on a CT scan. Patient 5 exhibited only dense lymphocytic infiltrate in the biopsy sample (4 points) and the highest serum IgG4 concentration range (11 points). In addition, this patient showed abnormalities in one set of glands ( 6 points) and in the renal pelvic soft tissue ( 8 points) on a CT scan.

In this study, we elucidated that $97.5 \%$ of the patients with definite IgG4-RD were also reclassified as having IgG4-RD according to the 2019 ACR/EULAR criteria in Korea. We also revealed that the biopsy result of the lymph nodes was a crucial negative factor for the classification of IgG4-RD despite the highest serum IgG4 concentration range. Patient 1 had experienced recurrent lymph node enlargement for 3 years. This patient underwent lymph node biopsy five times to exclude malignancies. During this period, the serum IgG4 concentration had consistently increased, and the last two biopsy samples showed markedly increased infiltrating IgG4+ cells counts. Therefore, this patient was diagnosed with IgG4-related lymphadenopathy $^{34}$ and received glucocorticoids and mycophenolate mofetil. ${ }^{5}$ We believe that this paper will be of interest to the readership of the journal because of its immediate clinical impact to patients with suspected IgG4-related disease, as well as our recommendations to physicians attempting to diagnose them. To the best of our knowledge, this is the first pilot study investigating the agreement between the comprehensive criteria and the 2019 ACR/EULAR criteria for IgG4-RD.

\section{Byung-Woo Yoo, ${ }^{1}$ Jason Jungsik Song, ${ }^{1,2}$ Yong-Beom Park, ${ }^{1,2}$} Sang-Won Lee ${ }^{1,2}$

'Division of Rheumatology, Department of Internal Medicine, Yonsei University College of Medicine, Seoul, South Korea

${ }^{2}$ Institute for Immunology and Immunological Diseases, Yonsei University College of Medicine, Seoul, South Korea

Correspondence to Professor Sang-Won Lee, Internal Medicine, Yonsei University College of Medicine, Seoul 03722, Korea (the Republic of); SANGWONLEE@yuhs.ac

Contributors B-WY and S-WL designed the report and wrote the paper; B-WY, JJS and S-WL participated in the data acquisition and interpretation; B-WY, Y-BP and

S-WL drafted and revised the manuscript; S-WL designed the concept and approved the final paper. All authors have taken care to ensure the integrity of this work, and the final manuscript has been seen and approved by all authors.

Funding The authors have not declared a specific grant for this research from any funding agency in the public, commercial or not-for-profit sectors.

\section{Competing interests None declared.}

Patient and public involvement Patients and/or the public were not involved in the design, or conduct, or reporting, or dissemination plans of this research.

\section{Patient consent for publication Not required.}

Ethics approval This study was approved by the institutional review board of Severance Hospital (4-2019-0695), which waived the requirement for obtaining written informed consent from the patients as this was a retrospective study.

Provenance and peer review Not commissioned; internally peer reviewed. (C) Author(s) (or their employer(s)) 2020. No commercial re-use. See rights and permissions. Published by BMJ.

$$
\text { Check for updates }
$$

To cite Yoo B-W, Song JJ, Park Y-B, et al. Ann Rheum Dis Epub ahead of print: [please include Day Month Year]. doi:10.1136/annrheumdis-2020-217086

Received 1 February 2020

Accepted 3 February 2020

Ann Rheum Dis 2020;0:1-2. doi:10.1136/annrheumdis-2020-217086

\begin{tabular}{llllllll}
\hline \multicolumn{2}{l}{ Table 1} & Patients who underwent biopsy on lymph node & & & \\
\hline Patients & Biopsy sites & $\begin{array}{l}\text { Histology } \\
\text { points }\end{array}$ & $\begin{array}{l}\text { Immunostaining } \\
\text { points }\end{array}$ & $\begin{array}{l}\text { Serum IgG4 } \\
\text { points }\end{array}$ & Image points & $\begin{array}{l}\text { Total inclusion } \\
\text { points }\end{array}$ & Images of organ involved \\
\hline 1 & Lymph node & 0 & 0 & 4 & 0 & 4 & Only lymph node \\
\hline 2 & Lymph node & 13 & 0 & 11 & 0 & 24 & Only lymph node \\
\hline 3 & Lymph node & 0 & 0 & 11 & 14 & 25 & $\begin{array}{l}\text { Septal thickening and renal cortex low-density } \\
\text { area }\end{array}$ \\
4 & Lymph node & 0 & 0 & 11 & 18 & 29 & Paravertebral lesion and renal pelvis soft tissue \\
\hline 5 & Lymph node & 4 & 0 & 11 & 14 & 29 & One set of gland and renal pelvis soft tissue \\
\hline
\end{tabular}


ORCID iD

Sang-Won Lee http://orcid.org/0000-0002-8038-3341

\section{REFERENCES}

1 Wallace ZS, Naden RP, Chari S, et al. The 2019 American College of Rheumatology/ European League against rheumatism classification criteria for lgG4-related disease. Ann Rheum Dis 2020:79:77-87.
2 Umehara H, Okazaki K, Masaki Y, et al. Comprehensive diagnostic criteria for IgG4related disease (IgG4-RD), 2011. Mod Rheumatol 2012;22:21-30.

3 Wick MR, O'Malley DP. Lymphadenopathy associated with IgG4-related disease: Diagnosis \& differential diagnosis. Semin Diagn Pathol 2018;35:61-6.

4 Cheuk W, Chan JKC. Lymphadenopathy of IgG4-related disease: an underdiagnosed and overdiagnosed entity. Semin Diagn Pathol 2012;29:226-34.

5 Kamisawa T, Zen Y, Pillai S, et al. Igg4-Related disease. Lancet 2015;385:1460-71. 